\title{
LETTERS
}

\section{European Scleroderma Study Group to define disease activity criteria for systemic sclerosis. IV. Assessment of skin thickening by modified Rodnan skin score}

\author{
G Valentini, S D’Angelo, A Della Rossa, W Bencivelli, S Bombardieri
}

Ann Rheum Dis 2003;62:904-905

$\mathrm{T}$ he European Scleroderma Study Group (EScSG) has recently identified three activity 10 point indices devoted to evaluating disease activity in systemic sclerosis (SSc) (table 1), ${ }^{1}$ which have been externally validated.

An activity index must rely on widely used methods. ${ }^{3}$ The whole series index includes the total skin score (TSS) evaluated according to the scoring method of Kahaleh et al (KTSS). ${ }^{4}$ Because, at present, the modified Rodnan TSS (mRTSS) $)^{5}$ is the method most widely used to assess skin induration in SSc, we considered that the mRTSS value should be included in the whole series index rather than the original KTSS.

For this purpose, we considered only the group of 152 patients with SSc from our original study (out of the total pool of 290 patients) whose data had been used to construct the initial whole series index-that is, those in whom all the parameters listed in the SSc whole series index had been evaluated. ${ }^{16}$ We followed a procedure similar to that used by Medsger et al, ${ }^{7}$ when obtaining mRTSS values from the original Rodnan TSSs. However, because both KTSS and mRTSS are based on a three point scale, we assigned a score to each of the 17 areas specified by the modified Rodnan system; this score was drawn from the data gathered for the evaluation of the KTSS. Moreover, we ruled out the values relating to the neck, back, and buttocks, and for the fingers, where the Kahaleh system requires two scores-that is, distal and proximal), we used the higher score.

In the 152 patients with SSc studied the KTSS ranged from 0 to 50 (median 18), while the mRTSS ranged from 0 to 44 (median 14). To identify the mRTSS value to consider in the whole series index, we followed the procedure used in our previous study. ${ }^{1}$ Therefore, we first identified which mRTSS values were significantly correlated in univariate analysis with our "gold standard" of disease activity (that is, the consensus activity score blindly given on clinical charts by protocol management members), the reliability of which had been demonstrated. All the mRTSS values between 10 and 20 were suitable cut off points (that is, a value from 11 to 21 identified patients with a higher consensus activity score). However, an mRTSS value of 14 performed best in multiple regression analysis with a regression coefficient (0.839) that was as high as the one previously obtained by us using the Kahaleh scoring system.

In conclusion, we propose to modify the original activity index (table 1) by changing the method used to assess the TSS and using a value of mRTSS $>14$.

\section{Authors' affiliations}

G Valentini, S D'Angelo, Second University of Naples, Italy A Della Rossa, W Bencivelli, S Bombardieri, Clinical Immunology/Rheumatology Units, Department of Internal Medicine, University of Pisa, Italy

Correspondence to: Professor G Valentini, U.O di Reumatologia, Edificio 3, Via Pansini, 5 Naples, Naples, Italy; gabriele.valentini@unina2.it

Accepted 22 January 2003

\section{REFERENCES}

1 Valentini G, Della Rossa A, Bombardieri S, Bencivelli W, Silman AJ, D'Angelo S, et al. European multicenter study to define disease activity criteria for systemic sclerosis. II. Identification of disease activity variables and development of a preliminary activity index. Ann Rheum Dis 2001;60:592-8.

2 Valentini G, Bencivelli W, Bombardieri S, D'Angelo S, Della Rossa A, Silman AV, et al. European Scleroderma Study Group to define disease activity criteria for systemic sclerosis. III. Assessment of the construct validity of the preliminary activity criteria. Ann Rheum Dis 2003; 62:ar023186

3 Fries JF, Hochberg MC, Medsger TA. Criteria for rheumatic diseases: different types and different functions. Arthritis Rheum 1994;37:454-62.

Table 1 Proposed EScSG disease activity indices for SSc

\begin{tabular}{lccc}
\hline Criteria & Whole series & dcSSc & IcSSc \\
\hline TTS $>20$ (Kahaleh's method) ${ }^{*}$ & 1.0 & & \\
Scleredema & 0.5 & & 0.5 \\
$\Delta$ Skin & 2.0 & 3.0 & 2.5 \\
Digital necrosis & 0.5 & & 1.0 \\
$\Delta$ Vascular & 0.5 & 2.0 & 1.0 \\
Arthritis & 0.5 & 1.0 & \\
$\Delta$ Articular/muscular & 0.5 & & 1.5 \\
$\downarrow$ Tico & 2.0 & 4.0 & 2.5 \\
$\Delta$ Cardiopulmonary & 1.5 & & 1.0 \\
ESR $>30$ mm/1st h & 1.0 & & 10.0 \\
Hypocomplementaemia (C3 and/or C4) & 10.0 & 10.0 & \\
Total maximum disease activity index & & & \\
\hline
\end{tabular}

*To be changed to mRTSS $>14$.

TTS, total skin score; TLCO, carbon monoxide transfer factor; ESR, erythrocyte sedimentation rate. 
4 Kahaleh MB, Sultany GL, Smith EA, Huffstutter JE, Loadholt CB, Le Roy EC. A modified scleroderma skin scoring method. Clin Exp Rheumatol 1986;4:367-9.

5 Clements P, Lachenbruch P, Seibold J, White B, Weiner S, Martin R, et al. Inter- and intraobserver variability of the total thickness score (modified Rodnan TSS) in systemic sclerosis. J Rheumatol 1995;22:1281-5.
6 Della Rossa A, Valentini G, Bombardieri S, Bencivelli W, Silman AJ, $D^{\prime}$ Angelo S, et al. European multicenter study to define disease activity criteria for systemic sclerosis. I. Clinical and epidemiological features of 290 patients from 19 centres. Ann Rheum Dis 2001;60:585-91.

7 Medsger TA, Silman AJ, Steen VD, Black CM, Akesson A, Bacon PA, et al. A disease severity scale for systemic sclerosis. Development and testing. J Rheumatol 1999;26:2159-67.

\title{
T cell epitopes of prothrombin in patients with antiphospholipid syndrome
}

\author{
K Yoshida, A Tsutsumi, Y Ohnishi, T Akimoto, H Murata, T Sumida
}

Ann Rheum Dis 2003;62:905-906

A ntiphospholipid syndrome (APS) is characterised by arterial and/or venous thrombosis and recurrent fetal loss in association with the presence of antiphospholipid antibodies (aPL). In addition to $\beta_{2}$-glycoprotein I, prothrombin (PT) is an important autoantigen recognised by aPL. PT is a coagulation proenzyme abundantly present in blood $(70-100 \mu \mathrm{g} / \mathrm{ml})$, and binds to negatively charged phospholipids such as phosphatidylserine. PT comprises two major domains, fragment-l (F-1) and prethrombin-l (Pre-1). We previously reported that antiprothrombin antibody $(\mathrm{aPT})$ is a mixture of antibodies against both F- 1 and Pre- 1 , and that there are significant clinical differences between anti-F- 1 and anti-Pre- $1 .{ }^{12}$
aPL, including aPT, are not mere serological markers of the disease, but are important players in the pathogenesis of APS. Therefore, antigen-specific immunosuppressive treatments, if developed, will help to prevent thrombosis in APS. We aimed to locate the T cell epitopes of PT on either F-1 or Pre- 1 , as an initial approach to understanding the mechanism of aPT formation, and to search for possible PT-specific immunosuppressive treatments.

Samples from 15 patients with systemic lupus erythematosus (SLE) were positive for aPT. Fourteen patients were taking prednisolone at a mean of $10.8 \mathrm{mg} /$ day (range 5.0-22.5). For T cell proliferation assays, samples from nine healthy volunteers served as controls.

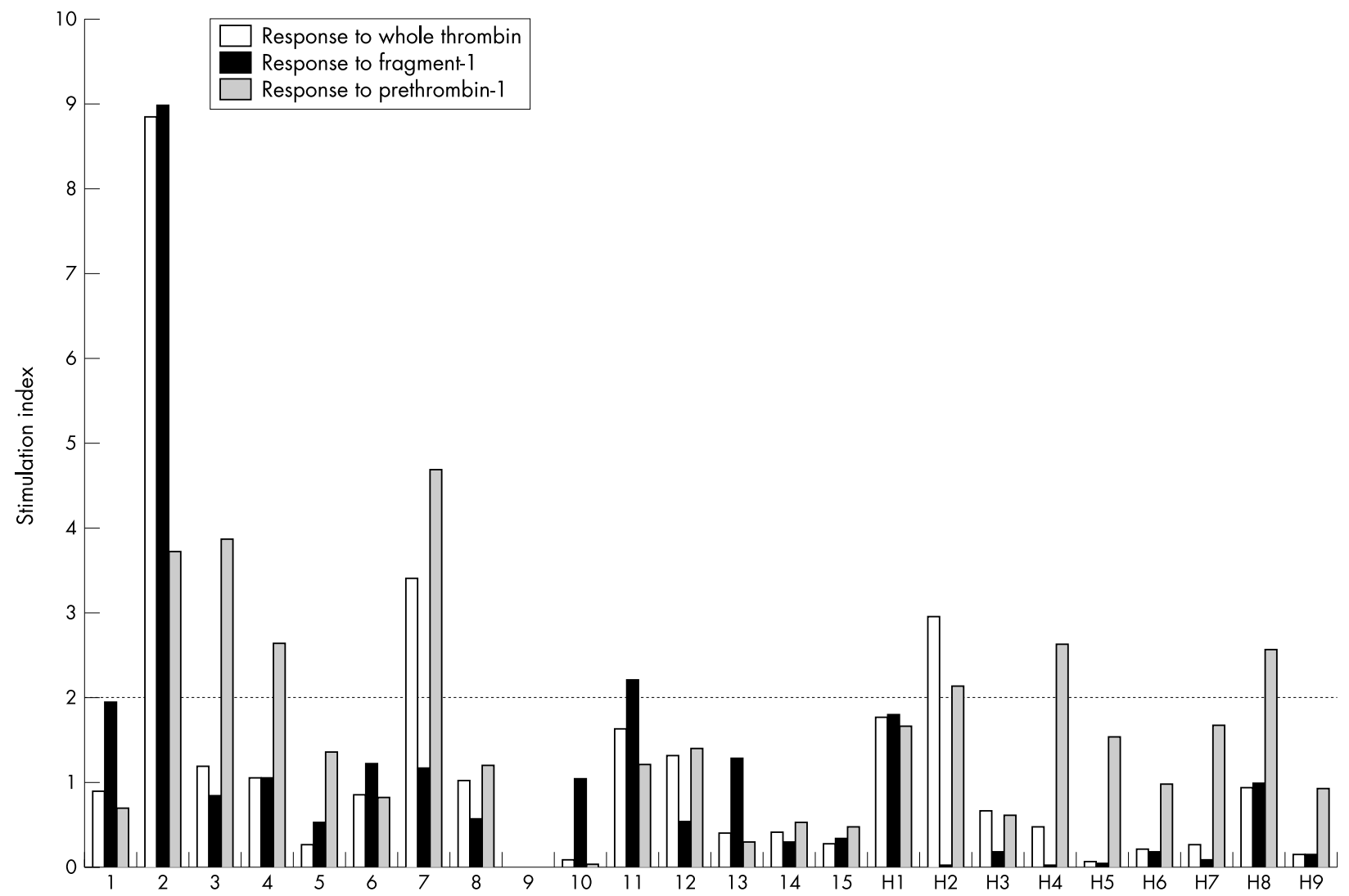

Figure 1 Proliferation of T cells stimulated by prothrombin. 1-15: subjects positive to antiprothrombin antibody; H1-H9: healthy controls. An $\mathrm{SI} \geqslant 2$ was considered positive. 
Table 1 Location of T and B cell epitopes on prothrombin, and HLA-DRB 1 allotypes in patients positive for antiprothrombin antibodies

\begin{tabular}{|c|c|c|c|c|c|c|c|c|c|c|c|}
\hline \multirow[b]{2}{*}{ Patient } & \multirow[b]{2}{*}{ Age/sex } & \multirow[b]{2}{*}{ Diagnosis } & \multirow[b]{2}{*}{ Symptom } & \multirow[b]{2}{*}{$a \beta_{2} G P I$} & \multirow[b]{2}{*}{ LAC } & \multirow[b]{2}{*}{ BFP } & \multicolumn{2}{|c|}{ B cell epitope } & \multicolumn{2}{|c|}{ T cell epitope } & \multirow[b]{2}{*}{ HLA-DRB 1} \\
\hline & & & & & & & F-1 & Pre-1 & $F-1$ & Pre-1 & \\
\hline 1 & $53 / \mathrm{F}$ & APS/SLE & $\mathrm{FL}$ & + & - & + & + & - & + & - & *0101/*0901 \\
\hline 2 & $60 / F$ & SLE & $P \mid+\downarrow$ & + & - & + & + & - & + & + & *1502/*1101 \\
\hline 3 & $29 / F$ & SLE & - & - & + & - & + & - & - & + & ${ }^{*} 1502 / * 0803$ \\
\hline 4 & $39 / F$ & SLE & - & - & - & + & + & - & - & + & *1101/*0901 \\
\hline 5 & $40 / F$ & SLE & $\mathrm{FL}$ & - & - & - & + & - & - & - & *1201/*0901 \\
\hline 6 & $31 / F$ & SLE & - & - & + & - & + & - & - & - & ${ }^{*} 0406 /{ }^{*} 1302$ \\
\hline 7 & $56 / \mathrm{F}$ & SLE & - & - & - & - & - & + & - & + & *1501/*0802 \\
\hline 8 & $68 / F$ & SLE & $\mathrm{T}$ & - & - & - & - & + & - & - & *1302/*1302 \\
\hline 9 & $26 / F$ & SLE & $P \mid \downarrow \downarrow$ & - & - & - & - & + & - & - & *1501/*0901 \\
\hline 10 & $30 / \mathrm{F}$ & SLE & $\mathrm{Pl} \downarrow \downarrow$ & - & - & - & - & + & - & - & *1501/*1501 \\
\hline 11 & $67 / F$ & SLE & - & - & - & - & + & + & + & - & ${ }^{*} 0101 / * 0803$ \\
\hline 12 & $31 / F$ & SLE & $\mathrm{T}, \mathrm{Pl} \downarrow \downarrow$ & - & - & - & + & + & - & - & *1501/*1402 \\
\hline 13 & $60 / \mathrm{F}$ & SLE & - & - & - & - & + & + & - & - & ${ }^{*} 14 \mathrm{~B} /{ }^{*} 1201$ \\
\hline 14 & $39 / F$ & SLE & $P \mid \downarrow \downarrow$ & - & - & - & + & + & - & - & ${ }^{*} 0802 /{ }^{*} 0401$ \\
\hline 15 & $42 / F$ & SLE & $\mathrm{Pl} \downarrow \downarrow$ & - & - & - & + & + & - & - & *1501/*1405 \\
\hline
\end{tabular}

SLE, systemic lupus erythematosus; APS, antiphospholipid syndrome; FL, recurrent fetal loss; $T$, thrombosis; Plt $\downarrow$, thrombocytopenia; a $\beta_{2}$ GPI anti- $\beta_{2}$ glycoprotein I; LAC, lupus anticoagulant (determined by dilute Russell's viper venom time ratio); BFP, biological false positive for serological test for syphilis; F-1, fragment-1; Pre-1, prethrombin-1.

Prothrombin was cleaved as described ${ }^{3}$ with some modifications. Briefly, $\mathrm{l} \mathrm{ml}(1.46 \mathrm{mg} / \mathrm{ml})$ of purified human PT (Haematologic Technologies, Essex Junction, VT) was incubated with $3 \mathrm{U}$ bovine thrombin (Itoham Foods, Osaka, Japan) for three hours at $37^{\circ} \mathrm{C}$. Cleaved products were run on sodium dodecyl sulphate-polyacrylamide gel electrophoresis, cut out, and purified using a model 422 Electro-Eluter (Bio-Rad, Hercules, CA).

Anti-PT, anti-Pre-1, and anti-F-1 enzyme linked immunosorbent assays (ELISAs) were performed as described previously. $^{3}$

For $\mathrm{T}$ cell proliferation assays, peripheral blood mononuclear cells $\left(2.0 \times 10^{5}\right.$ cells/well) were cultured in RPMI 1640 containing $10 \%$ fetal bovine serum and $1 \%$ L-glutaminepenicillin-streptomycin (Sigma), in the presence of PT, F-1 , Pre-1 $(1 \mu \mathrm{mol} / \mathrm{l})$ or controls, for three days under standard conditions. Antigen induced T cell proliferation was assayed by a cell proliferation ELISA, BrdU (Roche Diagnostics, Mannheim, Germany). The stimulation index (SI) was calculated as the mean optical density (OD) of wells containing the antigen/mean OD of the wells without antigen. An SI $\geqslant 2$ was considered positive.

Samples from only two patients showed positive responses to PT. Because a large amount of PT is present in sera, T cells may be rendered tolerant in normal conditions, or some modifications may be necessary for PT to be incorporated by antigen presenting cells. On the other hand, three samples showed positive responses to F-1, and four to Pre-1, indicating the presence of at least one T cell epitope in those domains (fig 1). Among the six patients with positive $T$ cell responses, the putative localisation of $\mathrm{T}$ and $\mathrm{B}$ cell epitopes was on the same domain in four patients, but was on different domains in two patients, suggesting that the location of T cell epitopes and the production of pathogenic aPT are not necessarily related (table $1)$.
HLA-DRB1*1501, which is suggested to be related to SLE, ${ }^{4}$ was present in 5/15 (33\%) patients. No significant skewing of the HLA-DRB1 alleles, or relationships with $\mathrm{T}$ cell epitopes were seen.

Samples from three controls showed positive responses to PT, F-1, or Pre-1. Autoantigen-specific T cells do exist in the sera of healthy subjects, ${ }^{5}$ and the presence of autoantigen reactive $\mathrm{T}$ cells by itself is not sufficient to cause autoimmune diseases, other factors are necessary.

Our study shows that PT-specific T cells present in aPT positive patients do not recognise a single common T cell epitope, and that $\mathrm{T}$ cell epitopes are different among individual patients.

\section{Authors' affiliations}

K Yoshida, A Tsutsumi, Y Ohnishi, T Akimoto, H Murata, T Sumida, Division of Rheumatology, Department of Internal Medicine, Institute of Clinical Medicine, University of Tsukuba, 1-1-1 Tennodai, Tsukuba 305-8575, Japan

Correspondence to: Dr A Tsutsumi; atsutsum@md.tsukuba.ac.jp

Accepted 27 January 2003

\section{REFERENCES}

1 Akimoto T, Akama T, Kono I, Sumida T. Relationship between clinical features and binding domains of anti-prothrombin autoantibodies in patients with systemic lupus erythematosus and antiphospholipid syndrome. Lupus 1999:8:761-6.

2 Akimoto T, Akama T, Saitoh M, Kono I, Sumida T. Antiprothrombin autoantibodies in severe preeclampsia and abortion. Am J Med 2001;110:188-91

3 Akimoto T, Akama T, Kono I, Yamane K, Sumida T. Detergent and antigen fragility affect the ELISA for measurement of anti-prothrombin autoantibodies. J Rheumatol 1999;26:580-7

4 Hashimoto H, Nishimura Y, Dong RP, Kimura A, Sasazuki T, Yamanaka $\mathrm{K}$, et al. HLA antigens in Japanese patients with systemic lupus erythematosus. Scand J Rheumatol 1994:23:191-6.

5 Hattori N, Kuwana M, Kaburaki J, Mimori T, Ikeda Y, Kawakami Y. T cells that are autoreactive to beta 2-glycoprotein I in patients with antiphospholipid syndrome and healthy individuals. Arthritis Rheum 2000;43:65-75. 


\title{
Transforming growth factor $\beta 1$ gene (HSTGFB 1) nucleotide T869C (codon 10) polymorphism is not associated with prevalence or severity of rheumatoid arthritis in a Caucasian population
}

\author{
V Pokorny, J Chau, L Wu, S Yeoman, P Black, F McQueen, L McLean
}

Ann Rheum Dis 2003;62:907-908

$\mathrm{n}$ a recent report in the Annals Sugiura and colleagues found an association between rheumatoid arthritis (RA) and a single nucleotide polymorphism (SNP) of HSTGFBl at nucleotide (nt) +869 (T869C; nt position relative to GenBank accession X05839), a coding SNP producing a Leu $\rightarrow$ Pro substitution in codon $10 .{ }^{1}$ The CC genotype was found in 29/155 (19\%) central Japanese patients with RA compared with 33/1 $10(30 \%)$ controls and this was significant when the CT and TT genotypes were pooled. Codon 10 is in the signalling peptide region and the Pro (869C) allele has been associated with higher transforming growth factor $\beta 1$ (TGF $\beta 1$ ) production. TGF $\beta 1$ is present in the synovial tissue of patients with $\mathrm{RA}$, and in addition to its profibrotic activities has regulatory effects on cells important in the pathogenesis of RA, including lymphocytes, dendritic cells, macrophages, chondrocytes, and osteoblasts. $^{2-5}$ Administration of TGF $\beta$ suppresses collagen induced arthritis, whereas antibodies to TGF $\beta$ exaggerate the process. ${ }^{6}$ Crilly and colleagues reported an increase in the high producing codon $10 \mathrm{Leu}$ (nt869T) in patients with systemic sclerosis. ${ }^{7}$ This polymorphism has also been associated with osteoporosis and with osteophytosis. ${ }^{89}$

\section{METHODS AND RESULTS}

To explore whether this polymorphism is associated with the prevalence and/or severity of RA in white patients, we used polymerase chain reaction (PCR) followed by restriction fragment length polymorphism (RFLP) analysis in 117 unrelated patients with RA and in 140 healthy blood donors matched for ethnicity with no known past or family history of RA or associated autoimmune disease. The patients were part of a prospective cohort who had been recruited within six months of their first RA symptom and characterised with detailed clinical, laboratory, radiographic, and immunogenetic assessments. ${ }^{10}$ Forty two patients were also examined with magnetic resonance imaging of the dominant wrist, as reported previously. ${ }^{11}$

Genomic DNA was amplified with PCR primers synthesised complementary to the genomic sequence, ${ }^{10}$ with an $\mathrm{A} \rightarrow \mathrm{T}$ mismatch introduced at position 25 of the reverse primer (complementing HSTGFBl nt872) to create a Pstl restriction enzyme recognition site with the $\mathrm{C}$ allele at nt869: TGF $\beta 1$ Leul0-forward 5' ACC ACA CCA GCC CTG TTC GC 3' and TGF $\beta 1$-Leul0-reverse 5'AGT AGC CAC AGC AGC GGT AGC AGC TGC $3^{\prime}$. With this change Pst 1 digests the 110 bp PCR product into 86 and 24 bp fragments only if the C allele is present. Sequenced controls for each of the three genotypes $\mathrm{CC}, \mathrm{CT}$, and TT were included to validate each digestion. To explore interactions between HSTGFBl nt869/codon 10 and HLA-DR "shared epitope" status, HLA-DRBl genotype was determined at high resolution by sequence based typing. Allele frequency data in $2 \times 2$ contingency tables were analysed with Fisher's exact test with the approximation of Woolf, genotype frequencies in $2 \times 3$ contingency tables were analysed with the $\chi^{2}$ test, and continuous variables of RA clinical sever-
Table 1 TGF $\beta 1$ nt869 (codon 10) genotype and allele frequencies in RA and control subjects

\begin{tabular}{lll}
\hline & $\begin{array}{l}\text { Patients with RA } \\
\text { No (\%) }\end{array}$ & $\begin{array}{l}\text { Controls } \\
\text { No }(\%)\end{array}$ \\
\hline TGFB1 nt869 genotype & & \\
TT & $32(27)$ & $41(29)$ \\
TC & $58(50)$ & $73(52)$ \\
CC & $27(23)$ & $26(19)$ \\
TGFB1 nt869 allele frequency & & \\
T & 0.52 & 0.56 \\
C & 0.48 & 0.44 \\
\hline
\end{tabular}

ity were compared between genotypic groups with the MannWhitney U test.

The nt869 allele and genotype frequencies were in Hardy-Weinberg equilibrium and did not differ between patients and controls (table 1). Median age of onset did not differ according to HSTGFBl nt869 genotype (TT 53 years, TC 48 , CC 56; NS). Within the prospective cohort of patients with early RA no difference was found according to HSTGF $\beta 1$ nt869 genotype for measures of disease severity over a two year period of follow up: IgM rheumatoid factor status (positive at $>40 \mathrm{IU} / \mathrm{ml}$ in $68 \%$ of CC genotype patients with RA $v 66 \%$ with CT and TT), erythrocyte sedimentation rate (27 and $28 \mathrm{~mm} / \mathrm{lst}$ $\mathrm{h}$ at baseline, 21 and $20 \mathrm{~mm} / \mathrm{lst} \mathrm{h}$ at two years), $\mathrm{C}$ reactive protein level ( 10 and $13 \mathrm{mg} / \mathrm{l}$ at baseline, 6 and $9 \mathrm{mg} / \mathrm{l}$ at two years), Health Assessment Questionnaire (0.50 and 0.60 at baseline, 0.20 and 0.20 at two years), disease activity scores (3.22 and 3.46 at baseline, 2.06 and 2.16 at two years), or the prescribing of disease modifying antirheumatic drugs (44\% and $51 \%$ at baseline, $73 \%$ and $73 \%$ at two years). Radiographic erosions were present in $24 / 116(21 \%)$ patients with RA at baseline, 50/112 (45\%) at one year, and 61/111 (55\%) at two years' follow up and did not differ according to TGF $\beta 1$ nt869 genotype. Radiographic data were incomplete for one, five, and six patients, respectively, owing to pregnancy or withdrawal from the study. Wrist magnetic resonance erosion, tendon, synovial, and contrast enhancement scores did not differ according to nt869 genotype. Stratifying the RA cohort according to HLA-DRB1 shared epitope (DRB1*0101, 0401, 0404, 0405, 0408, 1001, and 1402) status did not show any additional relationships. The signal sequence polymorphism at codon 25 (Arg $\rightarrow$ Pro; nt G915C) was also examined using PCR-RFLP (Sau96I), ${ }^{12}$ but similarly showed no association with RA prevalence or severity (data not included).

\section{DISCUSSION}

In this study of Caucasian patients with RA we did not confirm the association recently reported ${ }^{1}$ with HSTGFBl nt869/codon 10 in Japanese patients. This discrepancy may be due to the different ethnic populations studied; Japanese 
patients with RA have different HLA-DR associations (DRBI*0405, 0410) and, possibly, their non-HLA component is also different from that of Caucasian subjects.

This study cannot exclude a weak association. RA is a genetically complex disease, and it is likely that most of the non-HLA genes contributing to the approximately $50 \%$ genetic component in RA are individually very weak. To exclude a $4 \%$ difference between patients and controls (allele frequencies 0.48 and 0.44 , respectively, in our sample of 257 subjects) with $80 \%$ power at an $\alpha$ level of 0.05 would require testing over 2400 subjects in each group and $90 \%$ power would need 3200 in each group, beyond the scope of any published RA association genetics study. In addition, this study cannot exclude the possibility of an effect of other polymorphisms on RA, or an effect that may only be manifest when the nt869 SNP is present on the background of a particular extended haplotype. Several additional polymorphisms have been identified within or close to HSTGFBl, and further detailed study would be needed to exclude fully a contribution from this gene.

\section{ACKNOWLEDGEMENTS}

Supported by the Arthritis Foundation of New Zealand, the Auckland Medical Research Foundation, the Health Research Council of New Zealand, and the Lottery Grants Board.

\section{Authors' affiliations}

V Pokorny, J Chau, L Wu, F McQueen, L McLean, Department of Molecular Medicine and Pathology, University of Auckland, Auckland, New Zealand

L Wu, P Black, Department of Medicine, University of Auckland, Auckland, New Zealand

$S$ Yeoman, F McQueen, L McLean, Department of Rheumatology,

Auckland Hospital, Auckland, New Zealand
Correspondence to: $\operatorname{Dr~L~Mclean,~Experimental~Medicine,~AstraZeneca~}$ R\&D, Loughborough, Leics LE 11 5RH, UK ;

lachy.mclean@astrazeneca.com

Accepted 22 January 2003

\section{REFERENCES}

1 Sugiura Y, Niimi T, Sato S, Yoshinouchi T, Banno S, Naniwa T, et al. Transforming growth factor $\beta 1$ gene polymorphism in rheumatoid arthritis. Ann Rheum Dis 2002;61:826-8.

2 Fava R, Olsen N, Keski-Oja J, Moses H, Pincus T. Active and latent forms of transforming growth factor $\beta$ activity in synovial effusions. J Exp Med 1989;169:291-6.

3 Summers KL, O'Donnell JL, Heiser A, Highton J, Hart, DN. Synovial fluid transforming growth factor $\beta$ inhibits dendritic cell-T lymphocyte interactions in patients with chronic arthritis. Arthritis Rheum interactions in patien
1999:42:507-18.

4 Blobe GC, Schiemann WP, Lodish HF. Role of transforming growth factor $\beta$ in human disease. N Engl J Med 2000;342:1350-8.

5 OMIM, Online Mendelian Inheritance in Man. Transforming growth factor, $\beta$-1;TGFB 1;HSTGFB 1. http://www.ncbi.nlm.nih.gov/htbin-post/ Omim/dispmim?190180. Accessed 2002.

6 Kuruvilla AP, Shah R, Hochwald GM, Liggitt HD, Palladino MA, Thorbecke GJ. Protective effect of transforming growth factor $\beta 1$ on experimental autoimmune diseases in mice. Proc Natl Acad Sci USA 1991;88:2918-21.

7 Crilly A, Hamilton J, Clark CJ, Jardine A, Madhok R. Analysis of transforming growth factor $\beta 1$ gene polymorphisms in patients with systemic sclerosis. Ann Rheum Dis 2002;61:678-81.

8 Yamada Y, Miyauchi A, Goto J, Takagi Y, Okuizumi H, Kanematsu M, et al. Association of a polymorphism of the transforming growth factor- $\beta$, gene with genetic susceptibility to osteoporosis in postmenopausal Japanese women. J Bone Miner Res 1998;13:1569-70.

9 Yamada Y, Okuizumi H, Miyauchi A, Takagi Y, Ikeda K, Harada A. Association of transforming growth factor $\beta 1$ genotype with spinal osteophytosis in Japanese women. Arthritis Rheum 2000;43:452-60.

10 Pokorny V, Mclean L, McQueen F, Abu-Maree M, Yeoman S. Interferon-gamma microsatellite and rheumatoid arthritis. Lancet $2001 ; 358: 122-3$.

11 McQueen FM, Stewart N, Crabbe J, Robinson E, Yeoman S, Tan PL, Magnetic resonance imaging of the wrist in early rheumatoid arthritis reveals progression of erosions despite clinical improvement. Ann Rheum Dis 1999;58:156-63

12 Syrris P, Carter ND, Metcalfe JC, Kemp PR, Grainger DJ, Kaski JC, et al. Transforming growth factor-betal gene polymorphisms and coronary artery disease. Clin Sci 1998:95:659-67.

\title{
Acute, non-obstructive, sterile cholecystitis associated with etanercept and infliximab for the treatment of juvenile polyarticular rheumatoid arthritis
}

\author{
I Foeldvari, E Krüger, T Schneider
}

Ann Rheum Dis 2003;62:908-909

E tanercept and infliximab are soluble tumour necrosis factor $\alpha(\mathrm{TNF} \alpha)$ antibodies. Etanercept is approved for the treatment of polyarticular juvenile rheumatoid arthritis (JRA), and infliximab is in the process of being approved. We report the first case in which the same patient developed a non-obstructive, sterile cholecystitis with etanercept (Enbrel) and later with infliximab (Remicade).

\section{CASE REPORT}

A 15 year old white female patient with polyarticular JRA, treated with a combination of $14 \mathrm{mg} / \mathrm{m}^{2}$ methotrexate once a week intramuscularly and $2 \mathrm{~g}$ sulfasalazine a day, did not show any remission. Sulfasalazine was stopped, and $0.4 \mathrm{mg} / \mathrm{kg}$ etanercept twice a week subcutaneously was added. With this combination treatment the patient was in full remission after 4 weeks, but at 12 weeks her disease flared. Etanercept was increased to $0.5 \mathrm{mg} / \mathrm{kg}$ twice a week subcutaneously. Two weeks later she developed upper abdominal pain, nausea, and weight loss; she could not attend school. Gastroscopy showed a minimally active duodenitis and antrum gastritis. Histologically a helicobacter infection was proved. The abdominal sonography showed a thickened gall bladder with a halo sign. The laboratory tests showed normal lipase, aspartate aminotransferase, and alanine aminotransferase, but increased bilirubin $(20 \mu \mathrm{mol} / \mathrm{l})$. Despite eradication treatment against Helicobacter pylori, the symptoms were unchanged. A puncture of the gall bladder did not help to prove any infectious agent. Shortly after stopping etanercept, the abdominal symptoms resolved, and ultrasound showed a decrease of the thickness of the gallbladder wall.

Her arthritis flared, so infliximab was started at a dose of 3 $\mathrm{mg} / \mathrm{kg}$, and given at 0, 2, 4, 8, 14, and 20 weeks. Again her arthritis improved quickly. At week 20 the same upper abdominal pain and increase of bilirubin occurred as during etanercept treatment. The abdominal sonography again showed thickening of the gallbladder wall. Infliximab had to be stopped. A cholecystectomy was conducted, and the 
histology did not show any infectious agents. Four weeks after the operation she is free of abdominal symptoms.

\section{DISCUSSION}

An increase in the antinuclear antibody titre did not occur during the etanercept or infliximab treatment.

This is the first case of etanercept-and the third case of infliximab treatment-associated with acute non-obstructive cholecystitis. ${ }^{12}$ No signs of inflammation were found in the biopsy samples of our patient and the patient of Menghini et all. ${ }^{2}$ The patient reported on by Saleem et al had prominent bile duct damage and portal tract interface inflammation. ${ }^{1}$ The exact mechanism of this side effect in our patient is currently unclear, but rechallenge of the patient with two different TNF $\alpha$ blockers caused the same side effect, suggesting that the side effect is associated with the class of TNF $\alpha$ blockers.

\section{Authors' affiliations}

I Foeldvari, Paediatric Rheumatology Clinic at AK-Eilbek, 22081

Hamburg, Germany

E Krüger, T Schneider , Paediatric Clinic, LBK-Klinikum Heidelberg,

22417 Hamburg, Germany

Correspondence to: Dr I Foeldvari, Paediatric Rheumatology Clinic at AK-Eilbek, Friedrichsberger Str 60, D-22081 Hamburg, Germany;

sprechstunde@kinderrheumatologie.de

Accepted 21 January 2003

\section{REFERENCES}

1 Saleem G, Li SC, MacPherson BR, Cooper SM. Hepatitis with interface inflammation and $\lg G, \lg M$, and $\lg A$ anti-double stranded DNA antibodies following infliximab therapy: comment on the article by Charles et al. Arthritis Rheum 2001;44:1966-8.

2 Menghini VV, Arora AS. Infliximab-associated reversible cholestatic liver disease. Mayo Clin Proc 2001;76:84-6.

\section{EULAR NEWS}

\section{Report of EULAR Standing Committee on Epidemiology and Health Services Research: Lisbon, June 2003}

rin

$\mathrm{n}$ recent years at the EULAR annual congresses the standing committee has put together several interactive workshops on methodological issues in clinical epidemiology. This year we offered a mini-symposium on practical issues in descriptive epidemiological studies in the EULAR region. The symposium aimed at obtaining knowledge on various available sources, methods, and screening instruments; understanding the goals, advantages, and pitfalls of the various methods; contributing to the improvement and updating of knowledge on the distribution and determinants of rheumatic disease; and facilitating the generation of hypotheses.

In the autumn of 2001 the standing committee organised a successful course on clinical epidemiology, including clinical trials and selected topics. This was done in close cooperation with the Standing Committee for Education and Training and the Standing Committee for International clinical Studies, Including therapeutic Trials (ESCISIT). The EULAR executive board has agreed to support a second course in the spring of 2005. The venue will soon be announced. The number of participants will be limited to 40 . Young rheumatologists from Eastern European countries will be granted priority to participate.
After two terms in office as chairman of the standing committee, the current chairman of this committee will leave and Professor Francis Guillemin from Nancy, France, has now been ratified as the next chairman. Members of the committee mostly meet only once a year. It would facilitate the work if members were able to meet more often, but electronic communication can be used as substitute. Until now, time has been too short to get an e-journal club up and running among the members of the committee.

The prevalence study-a standing committee project-is progressing steadily. This project was discussed at the committee's meeting in Lisbon. Other topics that were dealt with included the EROS project (Dr T Roussou) and the World Health Organisation International Classification of Functions, Disability and Handicaps (WHO ICF) project (Professor G Stücki). Furthermore, EULAR has recently provided a grant for an international epidemiological study on the development of appropriate criteria for the psoriatic arthritides. At the Lisbon meeting of the standing committee Dr P Helliwell discussed this project with the members. Clearly, the current chairman leaves the committee in good shape.

$S$ van der Linden sli@sint.axm.nl 